\title{
RESEARCH ON THE EFFECT OF SOIL HEAVY METAL ELEMENTS IN THE POTENTIAL HABITATS OF GIANT PANDAS (AILUROPODA MELANOLEUCA)
}

\author{
ZHANG, C. ${ }^{1,2^{*}}-\mathrm{WU}, \mathrm{S} .{ }^{3^{*}}$ \\ ${ }^{I}$ School of Civil Engineering, Shandong Jiaotong University, Jinan 250000, P.R. China \\ ${ }^{2}$ College of Geography and Environment, Shandong Normal University, Jinan 250000, P.R. \\ China \\ ${ }^{3}$ Shandong Agriculture and Engineering University, Jinan 250000, P.R. China \\ ${ }^{*}$ Corresponding authors \\ e-mail:naonao81@126.com (Zhang, C.),wushuang2017007@126.com (Wu, S.)
}

(Received 20 $0^{\text {th }}$ Apr 2020; accepted 29 $9^{\text {th }}$ Jul 2020)

\begin{abstract}
By building a geochemical (heavy metal) niche model for giant pandas, this paper researched and analyzed the restriction of $\mathrm{Cr}, \mathrm{Hg}$ and $\mathrm{Pb}$ in the soil in Pingwu County, Sichuan Province on the giant pandas' selection of habitats. According to the model analysis, in this study area, $\mathrm{Cr}$ has the largest impact on the giant pandas' selection of habitats. In this habitat, the maximum bearing value of $\mathrm{Cr}$ is $70 \times 10^{-6} \mathrm{mg} / \mathrm{kg}$; the maximum bearing value of $\mathrm{Hg}$ is $462.8 \times 10^{-9} \mathrm{mg} / \mathrm{kg}$; and the maximum bearing value of $\mathrm{Pb}$ is $37.94 \times 10^{-6} \mathrm{mg} / \mathrm{kg}$. If the content of the above three heavy metal elements exceeds their respective maximum bearing value, the encounter rate of the giant pandas in this area will decrease to 0 , and the giant pandas will no longer choose this area as a habitat.
\end{abstract}

Keywords: endangered species, ecological niche model, habitat selection, pollutant, Pingwu County

\section{Introduction}

As a symbol of China, an endangered species and a world-class protected animal, the giant panda, Ailuropoda melanoleuca (David, 1869) receives much attention from the global scientific research circles. The heavy metal pollutants in a giant panda habitat enter and accumulate in the bodies of the giant pandas and other animals along the food chain, and thus pose a threat to their health and even life. To better select habitats for pandas and thus better protect them, we carried out this study. With an ecological niche model, we studied and analyzed how the three elements of $\mathrm{Cr}, \mathrm{Hg}$ and $\mathrm{Pb}$ in soil in Pingwu County of Sichuan restricted the habitat selection of pandas, to find out the influence of the content of the three heavy metallic elements in soil on the habitat selection of pandas under natural conditions, and finally determine an area in Pingwu County with a minimum influence of the three heavy metallic elements on pandas, as an effective reference for the habitat selection of pandas.

\section{General Situation of the Study Region}

The number of giant pandas in Sichuan Province takes up over $70 \%$ of the global wild pandas, while Pingwu County in Sichuan Province is honored as the number one county in the world for pandas. This location also appears to be an important transition zone between panda species A and B (Hu, 2005). The area belongs to the Himalayan-Hengduan Mountains, one of the core global biodiversity areas. The reserve maintains typical natural 
ecological systems and this one in particular is the most intact ecosystem within its latitude region. It has representation and typicality that is outstanding on a global scale.

\section{Review of Literature}

The influence of heavy metal elements on the giant pandas has been studied for a long time. For instance, Liu and Wang (1988) took 43 panda samples from Minshan Mountains and 10 from Qionglai Mountains, and then tested the normal value range of 10 trace elements, including $\mathrm{Pb}$, by analyzing the trace elements in the panda hair. A direct path for pollutants, including heavy metals, to enter the bodies of the giant pandas and other animals is their food bamboo (de Almeida Curi et al., 2012), thus many researches have been carried out based on the content of heavy metals in the food. For example, Wang (2011) tested how much different concentrations of $\mathrm{Pb}$ and $\mathrm{Cd}$ were absorbed and accumulated in 5 kinds of bamboos, including potted bamboo in laboratory and simulated black bamboo. Liu (2015) from Chinese Academy of Sciences analyzed the exposure of the endangered animals in Qinling Mountains, including giant pandas, to heavy metals $(\mathrm{Cr}, \mathrm{Pb}, \mathrm{Hg}$ and $\mathrm{As}$ ), and made a comparison in heavy metals between the habitats of the wild giant pandas and the giant pandas in captivity. Through research, Zheng et al. (2016) found that traffic could be an important source of heavy metallic pollution in soil in habitats of pandas, as expressways increased the concentration of toxic metal in these places. Tian et al. (2019) observed high potential risks to pandas that were exposed to $\mathrm{Pb}$, As and Hg in a study. Zhao (2019) found that concentrations of heavy metal in feces and bamboo samples were positively correlated, which meant that polluted bamboo could be a major direct source of pollutants to which pandas were exposed.

As mentioned above, some scholars have noticed the harmful impacts of heavy metals on the giant panda and other relevant endangered animals. In addition, to carry out an efficient analysis on the potential habitats of giant pandas, we have to consider the distribution of heavy metal elements in the study area. But at present, there are very few reports on the effect of heavy metal elements on the giant pandas' selection of habitats. So, this paper built a niche model of heavy metals, researching and analyzing the restriction of $\mathrm{Cr}, \mathrm{Hg}$ and $\mathrm{Pb}$ in soil on the giant pandas' selection of habitats, in hope of providing reference for analyses of giant panda habitats in future.

\section{Materials and Methods}

\section{Maximum Entropy and Niche Theory}

Niche theory can be used to explain and predict the distribution range of a giant panda habitat. The person who first proposed niche theory is Grinnell (1917), while the one who first treated niche theory mathematically is Hutchinson and Macarthur (1959). The core idea of mathematical treatment is that every organism is restricted by different factors in the natural environment, there is a suitable quantizing interval for all these factors, and the composite factors in the interval are concrete indexes for this organism's existence and multiplication. Species niche is a collection of the composite factors of all the intraspecific organisms. The concept of maximum entropy was proposed by Jaynes and Cummings (1963). Maximum entropy is derived from information science, and at present, it has been applied to economics, ecology and the relevant inter-disciplines. Maximum entropy has a good confinement effect on incomplete information-based probability distribution. Its purpose is to infer unknown information by full use of incomplete 
information, and take known information as a constraint value, with the probability distribution meeting the condition for entropy value maximization. Incomplete information comes from entropy theory, which was proposed by Shannon (1948). As the amount of information increases, entropy value decreases. When it is used for forecasting, no tendentious hypothesis will be made, but on the premise that the existing information is indeed contained, when the entropy value is maximized, redundant information will be completely excluded, so that the uncertainty of unknown information should be reduced. Set a random variable $\xi$, which may have $n$ possibilities, including A1, A2, A3,..An, and for the appearance of each possibility, there may be a probability, which equals to $\mathrm{p} 1, \mathrm{p} 2$, p3,..., pn, so the information entropy $\mathrm{H}(E q .1)$ is:

$$
H(\xi)=\sum_{i=1}^{n} p_{1} \log \frac{1}{p_{i}}=-\sum_{i=1}^{n} p_{i} \log p_{i}
$$

\section{MaxEnt Model}

Phillips et al. (2004) developed MaxEnt model based on the above maximum entropy and niche theory. According to the known distribution range of a species based on environmental factors, this model calculates the maximum entropy value corresponding to the distribution rule of this species, and predicts the potential distribution area of this species. That is, a constraint condition needs to be determined first in accordance with the environmental characteristics of the target species' habitat, and then the maximum entropy can be calculated in line with this constraint condition. The predicted distribution range of this species is the probability distribution of this species when entropy reaches its maximum.

Since its development by Phillips et al. (2004) MaxEnt model has gone on a good run and been used by many scholars to predict habitats of animals and plants. Prates-Clark et al. (2008) based on a maximum entropy model, researched the distribution law of three tree species in the Amazon Basin and predicted their distribution using MODIS data and other relevant remotely sensed data. Hernandez et al. (2006) discovered in their research that despite the limited number of biologic points, the result would also be reliable, and the precision could meet the requirements, suggesting that it is applicable despite a small number of sample points. With the constant improvement of the model, more and more people have applied it to the analysis of habitats. Thus, this paper constructed a niche for the giant pandas in Pingwu County using this mode.

\section{Niche Model for the Heavy Metals in the Habitat of Giant Pandas in Pingwu County}

\section{Data Source}

This paper primarily built a niche model for heavy metals with $\mathrm{Cr}, \mathrm{Hg}$ and $\mathrm{Pb}$ in the soil as analysis objects. The map data of heavy metals (Fig. 1) comes from a WWF topic: Follow-up Study of Evaluations on the Ecological Environment in the Habitat of Giant Pandas in Pingwu County; the data of giant panda distribution come from the routine monitoring of Xiaohegou Nature Reserve in Pingwu County.

Attribute of heavy metal element data is extracted from the geochemical element map of this region, and the comparison in grade between these three elements is shown in Fig. 2. 

-7984 -

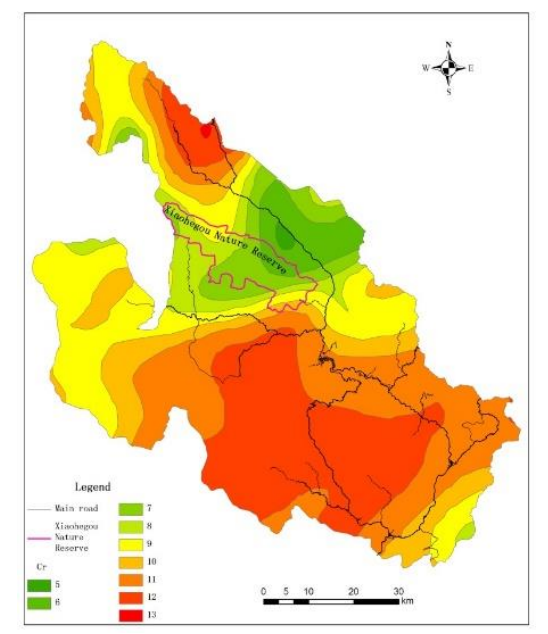

A. $\mathrm{Cr}$

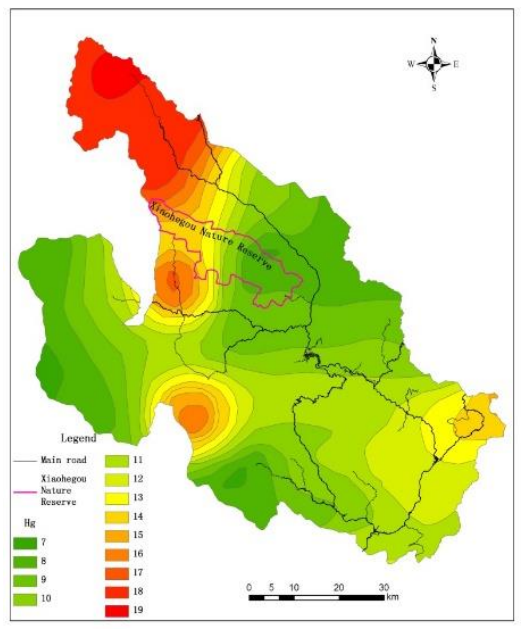

B. $H g$

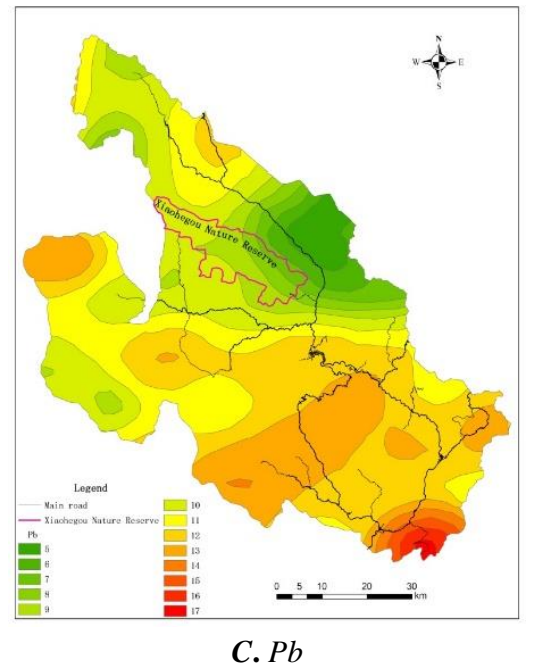

Figure 1. Distributionof Heavy metal in Pingwu

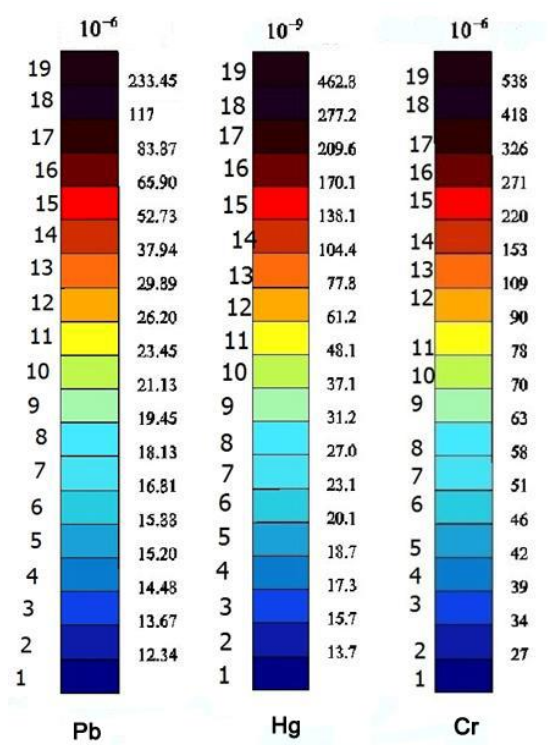

Figure 2. Element Grade and Content Comparison (element unit $\mathrm{mg} / \mathrm{kg}$ )

APPLIED ECOLOGY AND ENVIRONMENTAL RESEARCH 18(6):7981-7988.

http://www.aloki.hu • ISSN 15891623 (Print) • ISSN1785 0037 (Online)

DOI: http://dx.doi.org/10.15666/aeer/1806_79817988

(c) 2020, ALÖKI Kft., Budapest, Hungary 


\section{Result}

In Fig. 3, the horizontal ordinate indicates the variation range of heavy metal value, and the vertical coordinate shows a natural logarithm of heavy metal value's contribution to the suitability of the giant panda habitat. The value is directly proportional to habitat suitability, and for the giant pandas, the more suitable the habitat is, the higher their encounter rate is.

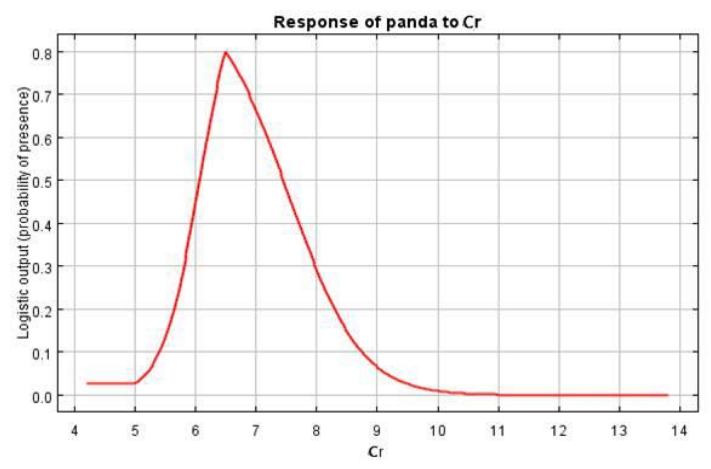

A. Response Curve of Cr to the Giant Panda Encounter Rate

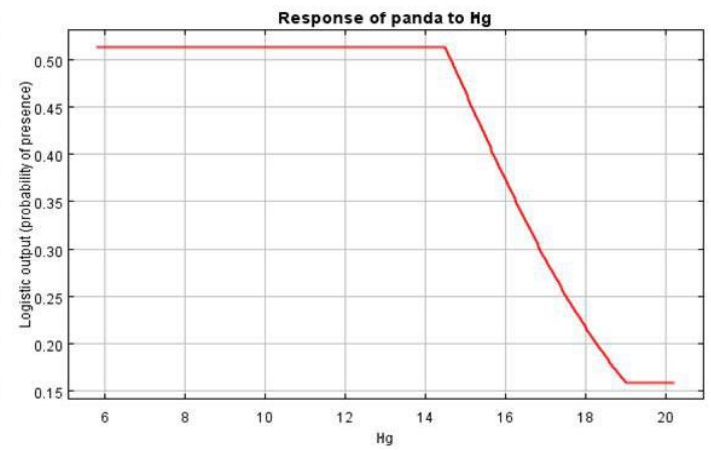

B. Response Curve of $\mathrm{Hg}$ to the Giant Panda Encounter Rate

Figure 3. Response Curve of $\mathrm{Cr}$ and $\mathrm{Hg}$ to the Giant Panda Encounter Rate

According to Fig. $3 \mathrm{~A}$, as $\mathrm{Cr}$ content increases to Grade $10\left(70 \times 10^{-6} \mathrm{mg} / \mathrm{kg}\right)$, the giant panda encounter rate decreases to 0 , suggesting that the maximum bearing value of $\mathrm{Cr}$ (Fig. 3B) in the habitat of giant pandas in this area is $70 \times 10^{-6} \mathrm{mg} / \mathrm{kg}$; before $\mathrm{Hg}$ content increases to Grade $15\left(138.1 \times 10^{-9} \mathrm{mg} / \mathrm{kg}\right)$, the probability of giant pandas' appearance is always stable, but as $\mathrm{Hg}$ content increases to $19\left(462.8 \times 10^{-9} \mathrm{mg} / \mathrm{kg}\right)$, this probability keeps decreasing to 0 from time to time, suggesting that $\mathrm{Hg}$ has a great effect on giant pandas. This effect is not obvious when $\mathrm{Hg}$ content is lower than $138.1 \times 10^{-9} \mathrm{mg} / \mathrm{kg}$, but if it's higher than $138.1 \times 10^{-9} \mathrm{mg} / \mathrm{kg}$, great harm will be done to the giant pandas. Maximum bearing value of $\mathrm{Hg}$ in the habitat soil in this area equals to $462.8 \times 10^{-9} \mathrm{mg} / \mathrm{kg}$.

As $\mathrm{Pb}$ content (Fig. 4) increases to Grade $14\left(37.94 \times 10^{-6} \mathrm{mg} / \mathrm{kg}\right)$, the giant panda encounter rate decreases to 0 . So, the maximum bearing value of $\mathrm{Pb}$ in the habitat soil in this area is $37.94 \times 10^{-6} \mathrm{mg} / \mathrm{kg}$. The contribution of these three elements is shown in Table 1 .

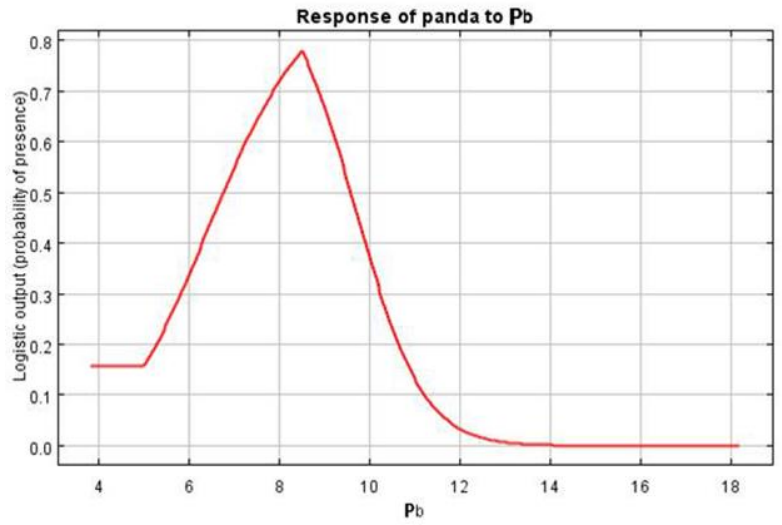

Figure 4. Response Curve of Pb to the Giant Panda Encounter Rate 
Table 1. Contribution of Heavy Metal Elements

\begin{tabular}{c|c}
\hline Cr contribution & 89.413 \\
$\mathrm{Hg}$ contribution & 2.033 \\
$\mathrm{~Pb}$ contribution & 8.554 \\
\hline
\end{tabular}

It can be seen from Table 1 that among these three heavy metal elements, $\mathrm{Cr}$ has the largest impact on the giant panda habitat, accounting for $89.413 \%$, followed by $\mathrm{Pb}$, accounting for $8.554 \%$; $\mathrm{Hg}$ has the least impact on the giant panda habitat in Pingwu County, accounting for $2.033 \%$. The result of the analysis by MaxEnt model is shown in Fig. 5.

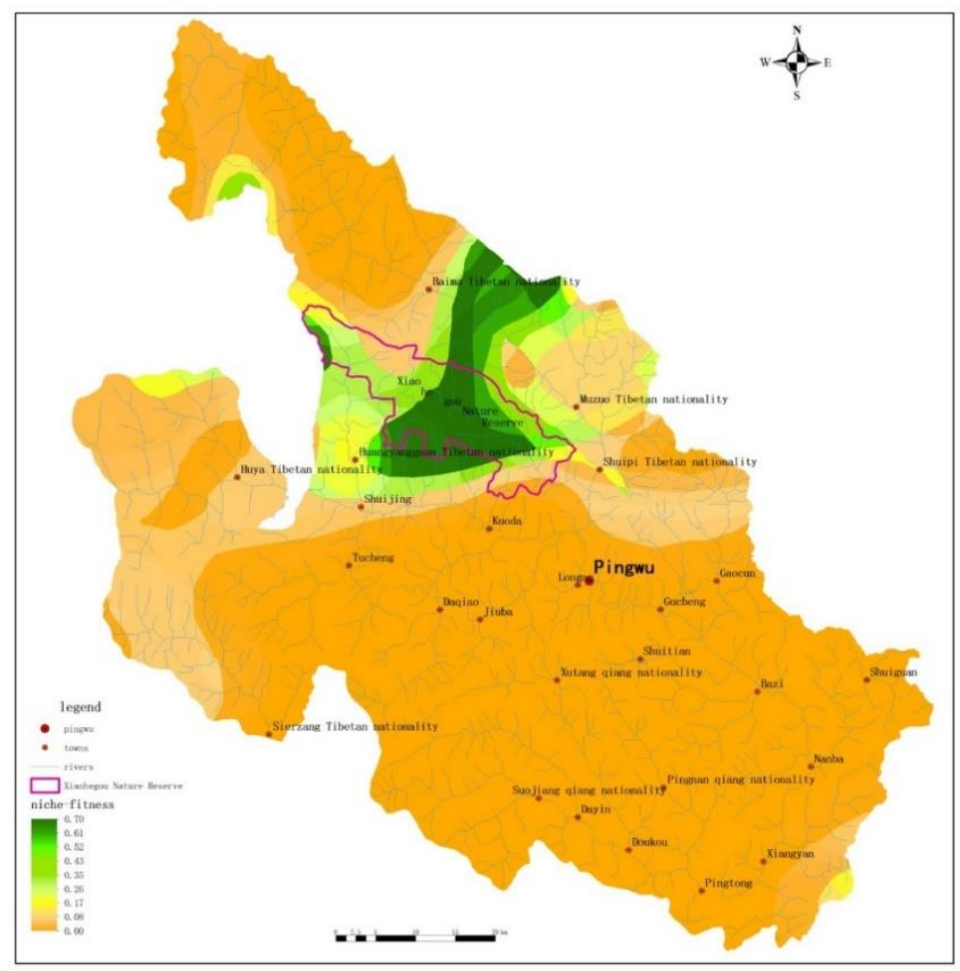

Figure 5. Suitable Region for MaxEnt Model

\section{Precision Evaluation of Operation Results}

For the giant panda habitat niche model, ROC (Receiver Operator Characteristic Curves) and AUC (the area under curves) were used to test the reliability of predicting outcomes. The larger the value is, the more strongly environment variables are correlated with the geographical distribution model of the predicted species, and the higher the predicting reliability is. AUC ranges from 0 to 1 , and its interval division is shown as follows: when AUC ranges between 0.5 and 0.7 , model evaluation is less reliable; when AUC ranges between 0.7 and 0.9, model evaluation is reliable; when AUC is greater than 0.9 , model evaluation is highly reliable. AUC is insusceptible to the threshold value, and the evaluation result is objective and has a wide application (Duan, 2015). In the heavy metal niche model, the AUC of the simulation result training set is 0.965 (Fig. 6), suggesting that the predictive effect is good, and the result is available. 


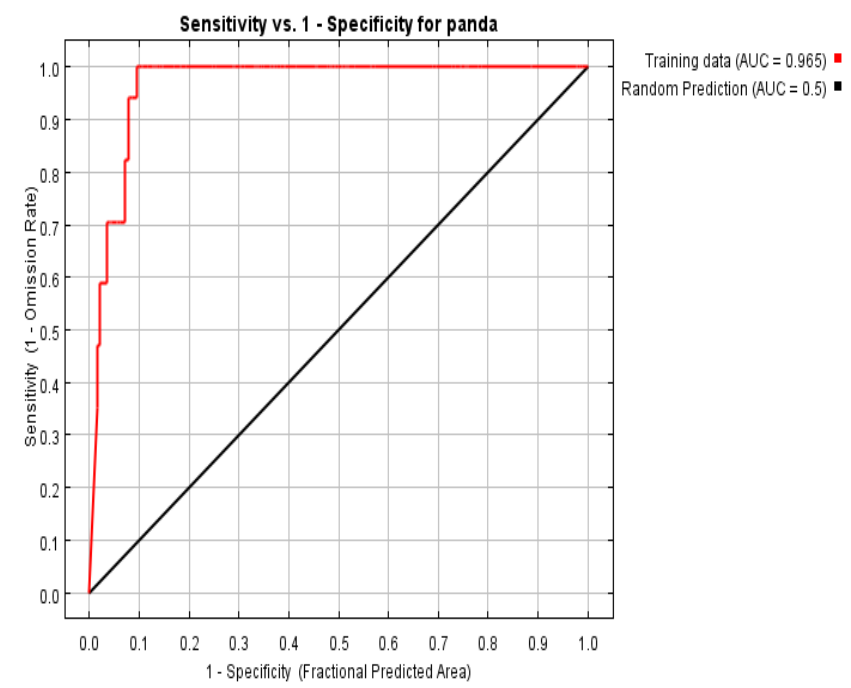

Figure 6. Predicting Result of Heavy Metal Niche Model ROC \& AUC

\section{Discussion}

Many scholars have their own opinions on wildlife conservation (Liu et al., 2018; Kija et al., 2020; Pédarros et al., 2020). Some of the contents and conclusions of this paper have been described in the author's previous Chinese articles (Zhang, 2016). But at present, there are very few reports on the effect of geochemical (heavy metal) elements on the giant pandas' selection of habitats. In order to provide reference for more researchers, we tried to extract part of the information, by building a geochemical (heavy metal) niche model, this paper researched and analyzed the restriction of $\mathrm{Cr}, \mathrm{Hg}$ and $\mathrm{Pb}$ in the soil in Pingwu County, Sichuan Province on the giant pandas' selection of habitats, and calculated the maximum bearing value of three elements in the giant panda habitat in the study area, in hope of providing reference for analyses of giant panda habitats in future. But due to the immaturity of the existing research on the mechanization of heavy metals' effect on the giant pandas, this paper suggests just taking it as an appropriate reference for the selection of potential habitats, rather than taking it as the main judgment basis for predictions of potential habitats in order to avoid ignoring the areas containing over-high bearing capacity. This paper studied the influence of the content of the three heavy metallic elements in soil on the habitat selection of pandas. The analysis shows that the content of heavy metal in soil will finally influence the habitat selection of pandas, which coincides with the research findings of Tian et al. (2019) that "we should attach greater importance to regional heavy metal pollution to protect this animal species". Major limitations of this paper lie in that the study fails to include other factors in this region such as the content of heavy metal in plants and the feces or hair samples of this targeted species, which will be further discussed in follow-up research.

\section{REFERENCES}

[1] Chao, Z. (2016): Study on the giant pandas' potential habitat based on "3S" technologytaking Xiaohegou nature reserve in Pingwu as an example. - Chengdu University of Technology. (in Chinese). 
[2] David, A. (1869): Extrait d'une lettre du meme, datke de la Principautk Thibetaine (independente) de Mou-pin, le 21 Mars. - Now Arch Mus Hist Nat Paris, Bull 5: 12-13.

[3] de Almeida Curi, N. H., Hoff Brait, C. H., Filho, N. R. A., Talamoni, S. A. (2012): Heavy metals in hair of wild canids from the Brazilian Cerrado. - Biological Trace Element Research 147(1-3): 97-102.

[4] Duan, S. W. (2015): Study on the Distribution and Prediction of Emberizajankowskii Based on Maxent Model. - Northeast Normal University, China.

[5] Grinnell, J. (1917): Field Tests of Theories Concerning Distributional Control. - American Naturalist 51(602): 115-12.

[6] Hernandez, P. A., Graham, C. H., Master, L. L., Albert, D. L. (2006): The effect of sample size and species characteristics on performance of different species distribution modeling methods. - Ecography 29(5): 773-785.

[7] Hu, J. C. (2005): Comprehensive Scientific Survery Report of the Xiaohegou Nature Conservation. - Chengdu, Sichuan Science and Technology Press. (in Chinese).

[8] Hutchinson, G. E., Macarthur, R. H. (1959): A Theoretical Ecological Model of Size Distributions Among Species of Animals. - American Naturalist 93(869): 117-125.

[9] Jaynes, E. T., Cummings, F. W. (1963): Comparison of quantum and semiclassical radiation theories with application to the beam maser. - Proceedings of the IEEE 51(1): 89109.

[10] Kija, H. K., Ogutu, J. O., Mangewa, L. J., Bukombe, J., Nzunda, E. F. (2020): Spatiotemporal changes in wildlife habitat quality in the greater serengeti ecosystem. Sustainability 12(6): 2440.

[11] Liu, D. Y., Wang, C. M. (1988): The giant panda body hair - analysis method. - Journal of China West Normal University Natural Sciences 9(2): 118-123. (in Chinese).

[12] Liu, Q. (2015): Exposure risk assessment of Qinling Endangered animals to heavy metals and pollution source apportionment. - University of Chinese Academy of Sciences. (in Chinese).

[13] Liu, C., Newell, G., White, M., Bennett, A. F. (2018): Identifying wildlife corridors for the restoration of regional habitat connectivity: A multispecies approach and comparison of resistance surfaces. - Plos One 13(11): e0206071.

[14] Pédarros, É., Coetzee, T., Fritz, H., Guerbois, C. (2020): Rallying citizen knowledge to assess wildlife occurrence and habitat suitability in anthropogenic landscapes. - Biological Conservation 242: 108407

[15] Phillips, S. J., Dudik, M., Schapire, R. E. (2004): A maximum entropy approach to species distribution modeling. - International Conference on Machine Learning, pp. 655-662.

[16] Prates-Clark, C. D. C., Saatchi, S. S., Agosti, D. (2008): Predicting geographical distribution models of high-value timber trees in the Amazon Basin using remotely sensed data. - Ecological Modelling 211(3-4): 309-323.

[17] Shannon, C. E. (1948): A mathematical theory of communication 2. - Bell System Technical Journal 27(3): 3-55.

[18] Tian, Z., Liu, X., Sun, W., Ashraf, A., Zhang, Y., Jin, X., He, X., He, B. (2019): Characteristics of heavy metal concentrations and risk assessment for giant pandas and their habitat in the Qinling mountains, China. - Environmental Science and Pollution Research 27(8-9): 1569-2584.

[19] Wang, B. (2011): Study of heavy metals lead and cadmium on the acumulation andtolerance of bamboos. - Shandong Agricultural University. (in Chinese).

[20] Zheng, Y. J., Chen, Y. P., Maltby, L., Jin, X. L. (2016): Highway increases concentrations of toxic metals in giant panda habitat. - Environmental Science and Pollution Research 23(21): 21262-21272. 